\title{
Flavour intensity of some edible fungi
}

\author{
RAKEL KURKELA and EILA MATIKAINEN
}

\begin{abstract}
KURKELA, R. \& MATIKAINEN, E. 1978: Flavour intensity of some edible fungi. - Karstenia 18 (suppl.).

The dilution indices of eight mushroom species - Agaricus bisporus, Boletus edulis, Suillus luteus, Lactarius torminosus, Lactarius trivialis, Cantharellus cibarius, Clitocybe nebularis and Lepista nuda - were determined by tasting the juice separated from Clitocybe nebularis and Lepista nuda - were determined by tasting the juice separated from
frozen and melted mushrooms. The duo-trio test and a panel of seven subjects were used for determining the recognition threshold of mushrnam flavour:

The dilution indices calculated from the most frequent threshold values varied from $0.024 \%(1 / 4160)$ for Clitocybe nebularis to $0.1 \%(1 / 1000)$ for Lactarius torminosus and Suillus luteus. The former was significantly greater $(P=0.01)$ and the latter two significantly smaller $(P=0.05)$ than the others, when the significance of the differences between the indices received from seven subjects was tested by the rank-order method.
\end{abstract}

R. Kurkela \& $E$. Matikainen, Department of Food Chemistry and Technology, University of Helsinki, SF-00710 Helsinki 71, Finland.

\section{Introduction}

The flavour of fungi varies so widely in intensity that some of them can be eaten as a main dish, while others are best used in small amounts as a condiment, to give a pleasant mushroom flavour to the other ingredients: Agaricus bisporus and Cantharellus cibarius, for example, are known for their mild flavour; Clitocybe nebularis is one of the strongest flavoured.

It is important to know the flavour intensity of different mushrooms, compared to each other and to other food items, especially when they are used as condiments.

Tilgner's dilution index (1962, 1965) can be used to compare the flavour intensities of different foodstuffs without a standard reference. It denotes the sensitivity or recognition threshold of the foodstuff as a percentage or dilution ratio.

Thus a dilution index of $1 \%(1: 100)$ means that a flavour is just recognizable, when made up in a $1 \%$ water solution. So the lower the index, the stronger is the flavour.

To compare the flavour intensity of certain fungi, Tilgner's dilution indices were determined for eight species: one of them was a cultivated mushroom and seven were species of wild fungi growing in the forest.

\section{Experimental}

\section{Material}

The fungi (A. bisporus, Boletus edulis, suillus luteus, Lactarius torminosus, L. trivialis, C. cibarius, C. nebularis and Lepista nuda) were frozen to $-18^{\circ} \mathrm{C}$ and stored for half a year before being used as the material for this study.

\section{Panel and conditions}

The panel consisted of seven to nine female students aged 20 to 30 , with earlier experience in sensory evaluation. The tastings were made in partitioned booths with air conditioning $\left(20 \pm 2^{\circ} \mathrm{C}, \mathrm{rH} 40 \%\right)$ daily between 10 to 12 or 13 to 15 , but never less than two hours after their latest meal.

\section{Preparation and presentation of the samples}

$500 \mathrm{~g}$ of fungi were weighed and kept at room temperature for one hour. They were then heated in a micro -wave oven to inhibit the enzymes till they became peroxidase-negative. The juice was separated from the solid particles by filtering through gauze. The dry -matter contents of the juices are given in Table 1 .

The juices were diluted with distilled water for tasting. The samples were served in glasses covered with aluminium foil.

\section{Procedure}

Preliminary study. The odour, taste and flavour thresholds of two extreme species of fungi were determined separately so as to train the panelists to distinguish the mushroom flavour, and select the dilution and tasting procedure for the main study. In the main study, sniffing would have been enough if the odour threshold had been significantly smaller than the taste threshold.

Single-sample presentation and ascending concentration series of the mushroom dilutions were used. The subject was asked to indicate the sample in which she could recognize a mushroom odour or taste.

The odour threshold of both species was determined by sniffing, the taste threshold by tasting 
with the nose blocked by nose-clips, and the flavour threshold by taking the sample orally without swallowing.

Table 1. The species studied, and their dry matter contents

Dry matter content of the juice\%

$\begin{array}{ll}\text { Agaricus bisporus } & 2.6 \\ \text { Boletus edulis } & 5.0 \\ \text { Suillus luteus } & 3.7 \\ \text { Lactarius torminosus } & 2.6 \\ \text { L. trivialis } & 2.2 \\ \text { Cantharellus cibarius } & 4.3 \\ \text { Clitocybe nebularis } & 2.9 \\ \text { Lepista nuda } & 4.5\end{array}$

The two species used in the preliminary study were the weak-flavoured $A$. bisporus, and the strong -flavoured $C$. nebularis. The dilutions were: A. bisporus $0.02 / 0.05 / 0.1 / 0.2 / 0.5 / 1.0 / 1.5 \%, C$. nebutaris $0.001 /$ $0.0025 / 0.005 / 0.01 / 0.05 / 0.1 / 0.2 \%$.

Main study. A duo-trio test was employed to determine the threshold values of the dilution indices. Three samples were presented, one labelled reference (distilled water) and two coded samples, one of which was identical to the reference, the other being one of the mushroom dilutions. The order of presentation within each pair was randomized. The subject was asked to identify the odd sample. The lowest concentration at which the odd sample was correctly identified in at least two consecutive concentrations in the ascending concentration series, was taken as the sensitivity threshold. The recognition threshold was the lowest concentration at which the subject recognized the characteristic mushroom flavour. This was used for calculating the dilution index in ratio.

The concentrations of mushroom juices were selected in such a way that the thresholds would come roughly at the middle of the concentration ranges. The concentrations used (percentages of mushroom juice in the solutions) were as follows:
A. bisporus: $3.0 \times 10^{-2 / 7.5 \times 10^{-2} / 1.5 \times 10^{-2} / 3.0 \times 10^{-1} /}$ $7.5 \times 10^{-1 / 1.5 \%}$
B. edulis: $\quad 2.7 \times 10^{-2 / 3.3 \times 10^{-2} / 6.6 \times 10^{-2} / 1.3 \times 10^{-1} /}$ $2.7 \times 10^{-1} \%$
S. Iuteus: $\quad 5.0 \times 10^{-2} / 1.0 \times 10^{-1 / 2} / 0 \times 10^{-1} / 4.0 \times 10^{-1} / 1.0 \%$
L.torminosus: $\quad 2.5 \times 10^{-2} / 3.3 \times 10^{-2} / 5.0 \times 10^{-2} / 1.0 \times 10^{-1}$, $1.3 \times 10^{-1} / 2.0 \times 10^{-1 / 4.0} \times 10^{-1} \%$
L. trivialis: $4.8 \times 10^{-2} / 9.5 \times 10^{-2} / 1.9 \times 10^{-1 / 3.8} \times 10^{-1}$, $9.5 \times 10^{-1} \%$
c. cibarius: $3.6 \times 10^{-2} / 5.9 \times 10^{-2} / 9.0 \times 10^{-2} / 1.8 \times 10^{-1} /$ $3.6 \times 10^{-1} / 9.0 \times 10^{-1} \%$

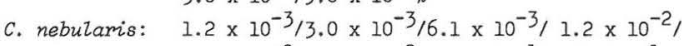 $2.4 \times 10^{-2} / 6.1 \times 10^{-2} / 1.2 \times 10^{-1 / 2.4 \times 10^{-1} \%}$

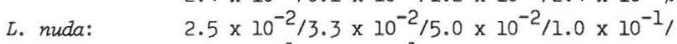 $2.0 \times 10^{-1} / 3.3 \times 10^{-1} \%$

Data analysis

The dilution indices for the mushroom species were calculated from the most frequent threshold values received for the eight subjects. To test the significance of the differences of flavour intensity between the species, these were arranged in descending order of the threshold values obtained for the tasters (ascending flavour intensity) (Kramer \& Twigg 1970). The significance of the differences of the rank totals was tested using Kahan et al.'s tables (1973).

$\underline{\text { Results }}$

Preliminary study. The thresholds for A. bisporus were determined by three procedures: odour threshold by sniffing only, taste threshold by tasting with the nose blocked, and flavour threshold by tasting orally in the normal way. For $C$. nebularis only the odour and flavour thresholds were determined. The odour, taste and flavour thresholds varied within similar ranges (Table 2 ).

In ten of the thirteen cases the mushroom flavour was recognized in lower concentrations when taken orally than when sniffed. For this reason the thresholds for the flavour dilution indices were determined in the main study by tasting orally in the normal way.

Main study. The mushroom-flavour recognition thresholds of eight species obtained for seven panelists are shown in Table 3. On comparing the panelists we find that one of them (E) differed significantly being less sensitive than the others six, who were very uniform. The dilution indices and ratios of eight mushroom species calculated according to the most frequent (i.e. typical) thresholds are given together with their dry matter contents, in Table 4 in order of flavour intensity. $c$. nebularis had the strongest flavour (lowest index), and L.torminosus and S. Iuteus the weakest.

To test the significance of the differences, the species were arranged in order of the thresholds of the seven subjects (Table 5). Using Kahan et al.'s tables

Table 2. Recognition thresholds of mushroom aroma and taste in the juice of Agaricus bisporus and clitocybe nebularis

Odour threshold

Taste threshold (nostrils closed)

Flavour threshold (normal orally)

1) Five judges

2) Eight judges

\begin{tabular}{|c|c|} 
A. bisporus & C.nebularis \\
\hline $0.05-1.0 \%$ & $0.02-0.05 \%$ \\
$0.05-0.5 \%$ & \\
$0.05-0.2 \%$ & $0.02-0.1 \%$
\end{tabular}


Table 3. Recognition thresholds of mushroom flavour in water dilutions for eight mushroom species using seven subjects

\begin{tabular}{|c|c|c|c|c|c|c|c|c|}
\hline 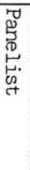 & 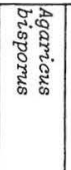 & 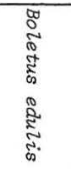 & 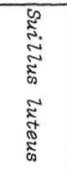 & 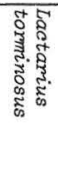 & 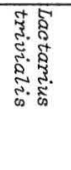 & 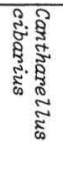 & 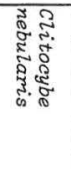 & 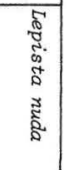 \\
\hline A & 0.15 & 0.066 & - & 0.10 & 0.095 & 0.09 & 0.024 & 0.05 \\
\hline$E$ & 0.30 & 0.27 & 0.400 & 0.13 & 0.95 & 0.9 & 0.12 & 0.33 \\
\hline G & 0.075 & 0.066 & 0.200 & 0.13 & 0.19 & 0.09 & 0.024 & 0.10 \\
\hline D & 0.15 & 0.27 & 0.100 & 0.05 & 0.095 & 0.09 & 0.024 & 0.033 \\
\hline $\mathrm{R}$ & 0.075 & 0.066 & 0.200 & 0.10 & 0.19 & 0.09 & 0.024 & 0.05 \\
\hline S & 0.075 & 0.066 & 0.100 & 0.05 & 0.095 & 0.09 & 0.024 & 0.03 \\
\hline V & 0.15 & 0.066 & 0.100 & 0.10 & 0.19 & 0.18 & 0.024 & 0.05 \\
\hline
\end{tabular}

Table 4. Typical dilution indices and dry-matter content of threshold dilutions for eight edible fungi. Seven panelists.

$\begin{array}{lclc} & \begin{array}{c}\text { Dilution } \\ \text { index } \%\end{array} & \begin{array}{l}\text { Dilution } \\ \text { ratio }\end{array} & \text { Dry matter } \% \\ \text { Clitocybe nebularis } & 0.024 & 1 / 4160 & 7 \times 10^{-4} \\ \text { Lepista nuda } & 0.033 & 1 / 3020 & 1.5 \times 10^{-3} \\ \text { Boletus edulis } & 0.066 & 1 / 1570 & 3.3 \times 10^{-3} \\ \text { Agaricus bisporus } & 0.075 & 1 / 1330 & 2.0 \times 10^{-3} \\ \text { Canthareltus cibarius } & 0.090 & 1 / 1110 & 3.8 \times 10^{-3} \\ \text { Lactarius trivialis } & 0.095 & 1 / 1050 & 2.1 \times 10^{-3} \\ \text { L. torminosus } & 0.10 & 1 / 1000 & 2.6 \times 10^{-3} \\ \text { Suillus Luteus } & 0.10 & 1 / 1000 & 3.7 \times 10^{-3}\end{array}$

(1973) the flavour intensisity of $C$. nebuzaris was found to be significantly $(P=0.01)$ stronger and that of L.torminosus and $S$. Zuteus significantly $(P=0.05)$ weaker than that of the others. From the dry matter contents in Table 4 it can be seen that, at the threshold, the dry matter content of $C$. nebularis was less than half of that of the others. This indicates that its stronger flavour does not depend on its higher dry matter content but on its stronger-flavoured constituents.

\section{Discussion}

Using the dilution ratios, we can compare the flavour intensities of the fungi with those of other foodstuffs. According to Tilgner (1962), the dilution indices of relatively mild-flavoured condiments, such as berry syrups and tomato concentrate, vary from 1/200 to 1/250; those of instant coffee, smoked fish and spices are $1 / 500,1 / 3000$ and around 1/30 000. The dilution indices
Table 5. Rank orders of dilution indexes for eight species of fungi. The results of seven judges, rank totals required for significance: $17-46 \mathrm{P}=0.05,14-49 \mathrm{P}=0.01$.

\begin{tabular}{|c|c|c|c|c|c|c|c|c|}
\hline 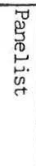 & 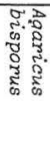 & 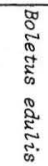 & 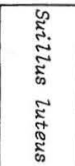 & 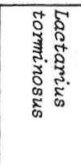 & 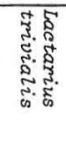 & 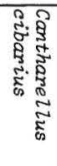 & 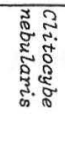 & 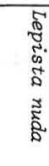 \\
\hline A & 1 & 6 & 2 & 3 & 4 & 5 & 8 & 7 \\
\hline$E$ & 5 & 6 & 3 & 7 & 1 & 2 & 8 & 4 \\
\hline G & 6 & 7 & 1 & 3 & - 2 & 5 & 8 & 4 \\
\hline D & 2 & 1 & 3 & 6 & 4 & 5 & 8 & 7 \\
\hline $\mathrm{R}$ & 5 & 6 & 1 & 3 & 2 & 4 & 8 & 7 \\
\hline $\mathrm{S}$ & 4 & 5 & 1 & 6 & 2 & 3 & 8 & 7 \\
\hline V & 3 & 6 & 4.5 & 4.5 & 1 & 2 & 8 & 7 \\
\hline \multicolumn{2}{|c|}{$\begin{array}{l}\text { Rank } 26 \\
\text { Total }\end{array}$} & 37 & $15.5^{x}$ & 32.5 & $16^{x}$ & 26 & $56^{x x}$ & 43 \\
\hline
\end{tabular}

\footnotetext{
${ }^{x}$ Significantly greater than others $(P=0,01)$

$\mathrm{x}_{\text {Significantly smaller than others }(P=0.01)}$
}

calculated from the recognition thresholds for 14 spices by Przędziecka and Baldwin (1976) varied from $1 / 67000$ to about $1 / 3000$. We find that the flavour intensity of fresh fungi is approximately the same as that of smoked fish and of mild spices such as Herba Majoranae (d.i. 1/2800) and Fructus carvi (d.i.1/4000), and ten times stronger than that of tomato concentrate.

\section{Acknowledgement}

The study was financed by the Academy of Finland.

\section{$\underline{\text { References }}$}

Kahan, G., Cooper, D., Paravasiliow, A. \& Kramer, A. 1973: Expanded tables for determining significance of differences for ranked data. - Food Technol. 27: 63-65, 68-69.

Kramer, A. \& Twigg, B. A. 1970: Quality control for food industry. 1: 489-500, 3rd Ed. Westport.

Przeździecka, T. \& Baldwin, Z. 1976: - Acta Alimentaria Polonica 2: 164-166.

Tilgner, D. J. 1962: Dilution test for odor and flavor analysis. - Food Technol. 16: 26-29.

-" 1965: Flavor dilution profilograms. - Food Technol. 19: 25-29. 